\title{
Prática pedagógica aliada ao aplicativo móvel zReader: efeitos sobre compreensão textual e interesse de crianças pela leitura
}

\author{
Tamila Kécia Nunes de Souza ${ }^{1}$, José Amancio Macedo Santos ${ }^{2}$, \\ Fabrício Vale de Azevedo Guerra ${ }^{1}$
}

${ }^{1}$ Departamento de Computação e Tecnologia

Universidade Federal do Rio Grande do Norte (UFRN) - Caicó, RN - Brasil

tamy.kecia, fabriciolo@gmail.com
${ }^{2}$ Departamento de Tecnologia - Universidade Estadual de Feira de Santana (UEFS) Feira de Santa - Ba - Brasil
zeamancioduefs.br

\begin{abstract}
This paper presents an experimental evaluation addressing the impact of zReader application on children's literacy. The intervention is formed by a a control group with 15 students and an experimental group with 17 students. It occurred during 11 months (from February to December 2019). Two variables were addressed: textual comprehension and interest in reading. For the textual comprehension, the results indicate improvement, but no statistical significant change. For the variable interest in reading, the results were very promising, with a statistically significant change for several items observed.
\end{abstract}

Resumo. Este artigo apresenta o resultado da avaliação experimental sobre o impacto do aplicativo zReader na alfabetização de crianças. A intervenção contou com um grupo de controle formado por 15 alunos e um grupo experimental formado por 17 alunos, e durou cerca de 11 meses (de fevereiro a dezembro de 2019). Duas variáveis foram consideradas: a compreensão textual e o interesse pela leitura. Para a variável compreensão textual, os resultados não apresentaram significância estatística, apesar de indicarem melhora nas médias obtidas. Para a variável interesse pela leitura, os resultados foram bastante promissores, apresentando significância estatística para vários itens observados.

\section{Introdução}

São notórios os problemas relacionados à alfabetização no Brasil e podemos ter uma boa ideia disso numa breve análise do último desempenho em leitura de estudantes do Terceiro Ano do Ensino Fundamental na Avaliação Nacional de Alfabetização [Brasil 2016] . A maioria das crianças do país encontra-se entre os níveis 1 e 2 da escala de proficiência da avaliação, níveis relacionados a habilidades mais básicas de leitura. Esses níveis, no entanto, não incluem habilidades essenciais de interpretação textual como a identificação de um pronome pessoal do caso reto (as crianças sabem ler ele ou nós, por exemplo, mas não sabem a quem esses pronomes referenciam dentro do texto) ou ainda a mera identificação dos interlocutores de um diálogo. Estamos falando de nada menos que 55\% de nossas crianças, e essa proporção é maior em algumas regiões, chegando a $70 \%$ na região Norte e $69 \%$ na região Nordeste. 
Em aspectos correlatos à compreensão textual, os dados também são desanimadores. Uma pesquisa em nível nacional, realizada pelo Instituto Pró-Livro em 2019 [Instituto Pró Livro 2019] , identificou tendência de decréscimo na frequência de leitura, especialmente na leitura por vontade própria de livros de literatura. Ademais, na faixa etária dos 5-10 anos, em particular, 33\% simplesmente não leem por vontade própria e 9\% leem menos de 1 vez por mês. Outro dado importante, ainda com relação a essa faixa etária, é o de que, entre as possibilidades elencadas pelas crianças como fator motivante para o ato de ler, $48 \%$ apontaram o gosto pela leitura como o principal fator, superando, em muito, itens como questões religiosas, exigência escolar e aprendizado pessoal, entre outros.

Desta forma, mesmo com todos os aparatos educacionais existentes, vemos que além de não dominarem certas habilidades com relação à leitura, os alunos dessa faixaetária demonstram problemas de frequência e interesse pela leitura. Problemas no desenvolvimento da leitura não são particulares do Brasil, na medida em que diversos pesquisadores de vários países utilizaram a tecnologia em propostas para endereçar questões relacionadas a melhorias na leitura. Takacs et al. fizeram uma revisão sistemática que resultou na análise de 43 desses trabalhos, trazendo generalizações importantes sobre efeitos de características específicas da tecnologia na leitura das crianças [Takacs et al. 2015]. Infelizmente, o trabalho conclui que alguns recursos tecnológicos, como a interatividade, podem causar malefícios com respeito ao desenvolvimento das habilidades de leitura das crianças, e alguns desses recursos, como uso de vídeo e som, proporcionam melhorias estatisticamente significativas, mas com efeitos pequenos e sobre tópicos específicos, como aquisição de vocabulário.

Diante de todo esse contexto, foi desenvolvido o aplicativo móvel zReader [Guerra et al. 2018]. O aplicativo é uma mistura de jogo e livro digital que demonstrou, em experimentos científicos, melhorias significativas com relação à compreensão textual e alguns comportamentos de leitura em crianças do ciclo de alfabetização. As melhorias incluem mais disposição para aprender a ler nas crianças do Primeiro Ano, maior evolução de compreensão textual em crianças do Segundo Ano e maior frequência de leitura em crianças do Terceiro Ano. A percepção de que o zReader apresenta resultados promissores no apoio à alfabetização de crianças cria espaço para novas investigações empíricas visando mitigar limitações referentes aos estudos previamente realizados. Considerando o paradigma experimental, este processo de mitigação de riscos à validade dos experimentos é parte natural do processo de produção de conhecimento empírico [Wohlin et al. 2012].

Com relação aos estudos prévios sobre o zReader [Guerra et al. 2019, Guerra et al. 2018], uma questão está relacionada ao fato de que os pesquisadores não puderam observar diferenças significativas na compreensão textual de crianças no Terceiro Ano e não discriminaram efeitos sobre muitas habilidades qualitativas de leitura. Outro aspecto é que o estudo não apresenta uma prática pedagógica consolidada de condução docente para uso do aplicativo com as crianças, provavelmente porque o trabalho foi desenvolvido por pesquisadores da área da Ciência da Computação. Não há, por exemplo, formas estabelecidas de instigar o aluno a pensar de forma crítica sobre o texto trabalhado no aplicativo: o procedimento testado nas pesquisas foi o de deixar que as crianças utilizassem o aplicativo livremente, fazendo intervenções reativas em caso de dúvidas de utilização ou perguntas gerais das crianças.

Assim, este trabalho apresenta um quase-experimento com a proposição de uma 
prática pedagógica de utilização do zReader. A prática é fundamentada em experiências e trabalhos da área de educação, centrando esforços na interação professor/aluno durante o uso da ferramenta. $\mathrm{O}$ objetivo geral é compreender como a prática pedagógica utilizando um recurso de cunho tecnológico pode contribuir para o desenvolvimento de habilidades e interesses referentes à leitura. Duas questões de pesquisa foram consideradas: 1) Quais as contribuições da prática pedagógica utilizando o zReader com relação a compreensão textual das crianças?; e 2) Quais os impactos da prática pedagógica utilizando o zReader no interesse das crianças pela leitura?

\section{2. zReader}

Com objetivo de dar suporte à compreensão textual e à frequêcia de leitura em crianças no ciclo de alfabetização, foi desenvolvido o aplicativo móvel zReader [Guerra et al. 2018]. $\mathrm{O}$ zReader funciona como uma biblioteca de livros-jogos nos quais as crianças podem fazer a leitura de uma narrativa textual, ver/analisar segmentos de desenhos animados baseados nos textos lidos, realizar tarefas literárias interativas e, por fim, gravar suas vozes num desenho animado montado durante as interações com o aplicativo, reinterpretanto a narrativa textual.

O software oferece diversos tipos de jogos-livros - que chamaremos simplesmente de jogos. Cada tipo de jogo tem suas próprias características e os jogos selecionados, dentro do zReader, para aplicação experimental, no âmbito deste trabalho, foram o TVid, para interações de leitura/interpretação textual e, em sequência, o RR, para a gravação dos desenhos montados a partir da interações do TVid. No TVid, as crianças lêem uma narrativa, página a página, como num livro digital convencional. Um exemplo de tela do TVid para uma narrativa particular pode ser visto na Figura 1 (A). A cada página lida, a criança pode acionar duas opções de animação (os retângulos na parte de baixo da Figura 1 (A)), animações que são exibidas na área de vídeo do joguinho, e deve escolher a opção de animação mais aderente ao texto lido.

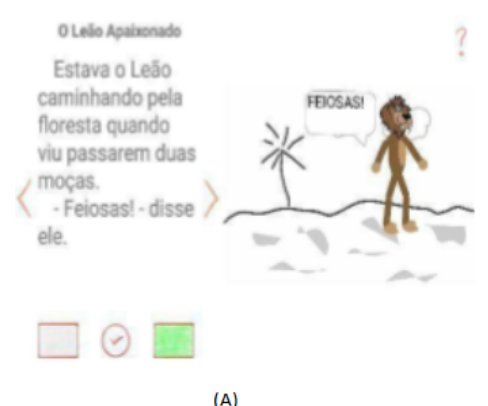

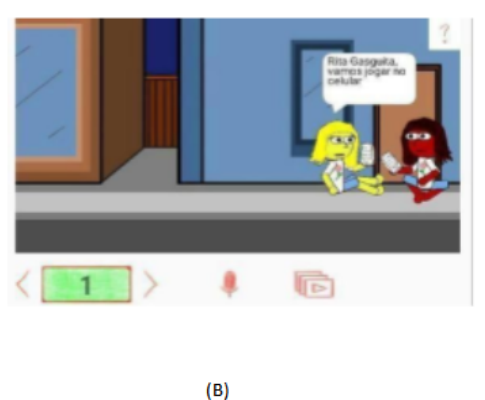

(B)

Figura 1. Tela do TVid (A) e da Sala de Gravação (B) do zReader

Lidas todas as páginas, a criança segue para Sala de Gravação, que é o jogo RR, onde ela simplesmente dubla todas as suas escolhas de animações feitas durante a leitura no TVid e gera um desenho animado completo. Assim, a criança realiza o reconto da história utilizando sua criatividade: vive personagens, narra ações e torna-se parte da narrativa que leu. A Figura 1 (B) ilustra a tela do RR para uma narrativa particular. 


\section{Prática pedagógica}

A contribuição central deste trabalho foi a definição de uma prática pró-ativa de uma dinâmica em sala de aula, com fundamentação pedagógica, que pudesse aliar-se à tecnologia zReader e servir como referência para sua adoção por profissionais da educação.

Desta forma, a dinâmica proposta e executada neste trabalho foi a de, a cada sessão de jogo, dividir uma turma em pequenos grupos ( 2 a 4 crianças) de modo que cada grupo ficasse com um tablet para jogar. A ideia foi a de obter a cooperação das crianças entre si na execução de uma tarefa [Libâneo 2013, p. 187] - no caso, em especial, a tarefa de interpretação do texto subjacente a cada jogo TVid, muito embora a experiência tenha demonstrado que as crianças também interagiram bastante na dublagem dos desenhos animados. Os alunos eram acomodados no chão da sala formando um único círculo. $\mathrm{O}$ texto era trabalhado de forma fragmentada, página a página, em consonância com a própria proposta do jogo TVid. Um aluno fazia a leitura em voz alta para toda a turma e os grupos escolhiam, em seus respectivos tablets, a opção que lhes parecesse correta, sempre de acordo com a dinâmica do joguinho. Após a conclusão da história, era realizado um debate, com toda a turma, acerca dos pontos principais do texto, para tirar dúvidas, compartilhar considerações sobre o que foi lido e saber se as crianças tinham compreendido bem a narrativa. Só então era feita a dublagem do desenho animado no RR, cada grupo isoladamente, e as crianças recontavam a história com base nas cenas que passavam na tela do joguinho. Cada aluno escolhia uma parte para recontar da forma que achasse melhor.

Toda essa dinâmica favoreceu intervenções pontuais junto às crianças ao longo da leitura. As intervenções eram realizadas com o intuito de provocar nas crianças a curiosidade sobre a história, além de criar situações-problema envolvendo as ações dos personagens com o cotidiano delas para que pudessem refletir sobre algumas posturas observadas ao longo dos dias dentro da escola. As perguntas eram relacionadas, em sua maioria, à realidade das crianças, da escola ou da comunidade. Segundo Teberosky and Colomer, isso faz com que elas reflitam sobre a situação e criem maneiras de solucionar os problemas propostos [Teberosky and Colomer 2003].

Essa mediação utilizada para internalizar determinados conhecimentos e assim desenvolver cada vez mais o aluno, proporcionando a superação dessa distância entre o que ele já sabe (Zona de Desenvolvimento Real) com o que ele poderá alcançar (Zona de Desenvolvimento Potencial), está relacionada à Zona de Desenvolvimento Proximal [Barra 2014].

Outrossim, a questão da leitura em voz alta executada pela criança foi pensada para que fosse possível analisar as dificuldades com relação à fluência de leitura e para que o aluno pudesse, segundo [Ferreiro and Teberosky 1985], se analisar enquanto leitor fazendo a relação entre o que está sendo visto, e o que se ouve.

Logo após a leitura do aluno, era realizada, também, a leitura em voz alta por parte da professora/pesquisadora, uma vez que, eventualmente, alguma criança fazia a leitura numa tonalidade baixa, por timidez ou por ter receio de errar algumas palavras mais complexas. A leitura em voz alta por parte de quem conduz a dinâmica é importante para esse processo de leitura das crianças pois, segundo [Teberosky and Colomer 2003], o aluno interage com o texto de forma diferente ao ouvir o que foi lido e poder fazer 
análises perante as ideias que estão sendo trabalhadas.

\section{Projeto do experimento}

Para alcançar os objetivos deste trabalho, foram utilizados procedimentos com base nas abordagens qualitativa e quantitativa. A pesquisa com base em técnicas de métodos mistos compreende o uso de mais de uma abordagem [Tatagiba 2012]. A utilização das duas abordagens se fez necessária pois as observações, teste e formulário realizados como instrumentos para a coleta de dados, foram importantes para entender melhor o problema. Foi utilizado neste trabalho o método da pesquisa-ação que está relacionada a uma estratégia onde o professor ou pesquisador, além de observar todo o processo, agirá perante a problemática existente revendo possíveis condutas com objetivo de contribuir positivamente para melhorar seu desempenho e de seus alunos [Tripp 2005].

Para entender como ocorreu todo o desenvolvimento do trabalho utilizamos uma pesquisa explicativa para demonstrar, através das observações feitas, o motivo de possíveis variáveis: "As pesquisas explicativas têm como propósito identificar fatores que determinam ou contribuem para a ocorrência de fenômenos. [...] pois tem como finalidade explicar a razão, o porquê das coisa" [Gil 2010].

\subsection{Procedimento, participantes e instrumentos para a coleta de dados}

Os participantes deste trabalho foram alunos de duas turmas, ambas do Terceiro Ano do Ensino Fundamental da Escola Municipal Walfredo Gurgel, na cidade de Caicó/RN: uma no turno matutino com 15 alunos e outra no turno vespertino com 17 alunos. Ambas tinham a mesma professora. As turmas foram divididas em 2 grupos. A da manhã foi o chamado grupo de controle, que não faria o uso da ferramenta, e a da tarde seria o grupo experimental, onde seria testada a prática pedagógica em conjunto com a ferramenta zReader. Dessa forma, não houve aleatoriedade na escolha entre as crianças que participariam (ou não) da intervenção, o que enquadra esse trabalho como um quase-experimento.

O desenvolvimento do trabalho se deu em quatro etapas, sendo a primeira destinada às observações da sala de aula do grupo experimental com intuito de conhecer o perfil da turma, saber qual o nível de intimidade que os alunos tinham com a leitura, além de perguntas a professora titular para saber como ela trabalhava a questão da leitura em suas aulas, quais as maiores dificuldades, e se todas as crianças já sabiam ler. "A técnica de observação pode ser muito útil para a obtenção de informações. Mais do que perguntar, podemos constatar um comportamento" [Prodanov and de Freitas 2013]. Visto isso, as observações não fizeram parte somente dessa parte inicial para entender os problemas, mas foi necessária durante todo o processo de aplicação (de fevereiro a outubro de 2019).

Na segunda etapa foi aplicado, abril de 2019, um Teste de Competência de Leitura de Palavras e Pseudopalavras (TCLPP), o chamado pré-teste, nas crianças de ambas as turmas, onde foi possível analisar em que nível de leitura e compreensão textual eles se encontravam. "O TCLPP é, ao mesmo tempo, um instrumento psicométrico e neuropsicológico cognitivo para a avaliação da competência de leitura silenciosa de palavras isoladas..." [Seabra and Capovilla 2010].

Ainda em abril de 2019, também como pré-teste, foi aplicado um formulário elaborado que "é o sistema de coleta de dados que obtém informações diretamente do entrevistado" [Prodanov and de Freitas 2013]. O formulário teve por finalidade entender os 
posicionamentos das crianças em relação à leitura, fazendo com que elas mesmas refletissem sobre diversos itens e se posicionassem sobre eles. As questões do formulário são apresentadas na Seção 5.2. O formulário foi alocado apenas ao grupo experimental.

Abrindo a terceira etapa, no final de abril de 2019, foi realizada a apresentação do zReader para os alunos do grupo experimental, seu objetivo, duração e forma de utilização. Logo em seguida, foi disponibilizado um momento para as crianças explorarem a ferramenta e tirarem dúvidas. Esta etapa se estendeu até outubro, com a realização de 11 práticas didáticas com a ferramenta nesse ínterim, uma história diferente sendo explorada a cada sessão e cada sessão durando certa de 80 minutos. As sessões eram realizadas sempre no horário de Língua Portuguesa, em substituição à prática da aula convencional. A turma era dividida em pequenos grupos de 3 ou 4 crianças, cada grupo usando um tablet Sangung Galaxy Tab com Android 5.1 instalado. A distribuição das crianças para cada grupo era realizada a cada aplicação e de forma que os alunos pudessem discutir e ter contato com diversos colegas.

Na quarta etapa foi reaplicado o teste e o formulário, como pós-teste, ambos em dezembro de 2019. O teste de compreensão textual foi realizado nas duas turmas e o formulário, que continha itens mais específicos para usuários da ferramenta, foi aplicado apenas à turma que utilizou o zReader.

A coleta de dados com pré e pós-testes possibilitou a análise das consequências da aplicação ao longo do ano com relação ao diversos aspectos qualitativos relacionados à leitura, comparando as percepções das crianças que usaram o zReader com as percepções delas próprias antes da ferramenta. Já a coleta de dados dos testes nos dois grupos possibilita a comparação da evolução em compreensão textual das crianças que usufruíram das práticas pedagógicas com o zReader em relação aos seus colegas que não usufruíram.

\section{Resultados}

Foi realizada uma análise estatística dos dados coletados com a realização do experimento para que fossem respondidas as questões de pesquisa deste trabalho. Revisando-as:

Questão de Pesquisa 1: Quais as contribuições da prática pedagógica utilizando o zReader com relação a compreensão textual das crianças?

Questão de Pesquisa 2: Quais os impactos da prática pedagógica utilizando o zReader no interesse das crianças pela leitura?

A análise compreendeu aspectos quantitativos, que envolveram as pontuações de compreensão textual das crianças, e compreendeu também aspectos qualitativos, que envolveram a evolução das percepções subjetivas das próprias crianças com respeito à relação delas com a leitura e, tangencialmente, com desenhos animados, que também estão presentes na ferramenta utilizada durante as práticas pedagógicas. Essas percepções foram acessadas a partir de um formulário de 15 itens, com respostas em escala Likert de 5 opções, ao passo que a compreensão textual foi quantificada a partir do teste TCLPP, conforme detalhado na Seção 4.1.

\subsection{Compreensão textual}

A compreensão textual foi aferida antes e depois das práticas (pré e pós-testes) com o zReader, e a evolução em termos de compreensão textual foi calculada como a diferença 
entre essas aferições. Como é natural que crianças no ciclo de alfabetização evoluam com respeito à compreensão textual, em virtude das aulas de língua portuguesa, foi utilizado um grupo de controle - onde a prática pedagógica ocorria sem o zReader.

A média da evolução da turma que participou da prática pedagógica, o chamado grupo experimental, mostrou-se maior que a média de evolução da turma que não trabalhou com o zReader (9,6 contra 7,0, em pontuação do teste TCLPP). Um teste estatístico, o teste-t [Johnston 1970], considerando as margens de erro, no entanto, deu não-significativo, o que, em princípio, não nos permite assegurar que essa diferença em evolução entre os participantes do experimento venha a estender-se para a população (em termos estatísticos) onde eles se inserem. Assim, em termos formais, a resposta para a Questão de Pesquisa 1 é a de que a prática pedagógica com a ferramenta, na frequência testada experimentalmente, não influencia a compreensão textual das crianças de uma forma geral.

\subsection{Interesse pela leitura}

O interesse pela leitura foi medido apenas entre as crianças que participaram das práticas pedagógicas com o zReader. As percepções delas quanto aos comportamentos de leitura, avaliadas após o término do experimento, foram comparadas com as mesmas percepções que elas tinham antes de começarem as práticas. Como estamos lidando com dados qualitativos e com relações de ordem - essencialmente, posicionamentos neutros, de concordância e de discordância - a comparação estatística entre as respostas antes e depois do experimento foi realizada através do método Delta de Cliff [Cliff 1993]. Assim como o teste t, o Delta de Cliff vai nos indicar se as diferenças (antes e depois) são significativas, ou seja, se elas devem acontecer novamente caso realizemos as práticas em outras crianças com o mesmo perfil. Vai nos dizer, também, em havendo diferenças, se elas são positivas ou negativas. Por fim, em havendo diferenças positivas ou negativas, o Delta de Cliff nos dará ainda, uma probabilidade disso acontecer, o chamado tamanho de efeito. Para potencial comparação futura com outros trabalhos que utilizem outros indicadores de tamanho de efeito, reportamos também uma interpretação dos tamanho encontrados entre os classificadores muito pequeno/pequeno/moderado/alto/muito alto/enorme [Sawilowsky 2009].

Ao todo, foram analisados 15 aspectos do interesse das crianças pela leitura (e algumas atividades relacionadas, presentes na ferramenta), todos eles descritos na Tabela 1 com respectivos resultados e classificadores. A tabela detalha os resultados para cada item, destacando textualmente a atitude inicial das crianças em relação a cada proposição (atitude neutra, negativa ou positiva) e efeitos das práticas sobre essa atitude inicial. Informalmente, uma atitude positiva indica frequência maior de respostas "concordo"e "concordo fortemente", uma atitude negativa indica uma frequência maior de respostas "discordo"ou "discordo fortemente"e uma atitude neutra indica seja uma frequência maior de respostas "neutro", seja equilíbrio entre frequências de respostas "concordo/concordo fortemente"e "discordo/discordo fortemente".

Assim, a Tabela 1 está organizada da seguinte forma: na primeira coluna é descrito o item que foi apresentado às crianças. As colunas valor-p e Delta Cliff apresentam o valor-p e o Delta de Cliff encontrados para cada item (nível de significância adotado para o valor-p: 0.05). A coluna pré-pós (\%) apresenta as chances de melhoria (símbolo $\uparrow$ ), manutenção $($ símbolo $=$ ) e piora (símbolo $\downarrow$ ) de atitude considerando valores de pré e 
pós testes. As duas últimas colunas apresentam a atitude prévia e um sumário do efeito resultante do teste. As linhas destacadas na tabela representam os itens em que houve signficância estatística, de acordo com Delta Cliff observado.

Houve influência positiva em 9 dos itens analisados: as crianças apresentaram uma atitude neutra, antes das práticas pedagógicas, em relação aos itens 4 (leitura no celular), 10 (identificação de diálogos em desenhos) e 14 (reflexão sobre ações de personagens), e uma atitude negativa em relação aos itens 5 (leitura no tablet), 6 (leitura no computador) e 11 (identificação de interlocutores de diálogos). Com as práticas pedagógicas, esses posicionamentos neutros e negativos se tornaram, todos, positivos, e o uso da Estatística Inferencial, disciplina onde se enquadra o método do Delta de Cliff, indica que esse efeito se sustenta caso as práticas sejam adotadas em outras crianças com o mesmo perfil. Mesmo itens sobre os quais, em geral, as crianças tinham prévia atitude positiva, as práticas acentuaram essa atitude, como no caso dos itens 3 (gostar de ler em casa), 12 (identificação de emoções em desenhos) e 13 (identificação de emoções em textos).

Há, ainda, 6 itens sobre os quais não se observou significância estatística em relação às diferenças encontradas nas amostras. O caso mais sensível provavelmente é o item 1, "eu gosto de ler", que merece uma análise mais profunda. Apenas três crianças de nossa amostra apresentavam atitude neutra ou negativa em relação a esse item, o que tornou bastante improvável a significância estatística no sentido esperado. Em todo caso, dessas três crianças, uma foi transferida de escola e não completou o experimento (não fez o pós-teste, portanto), uma passou de "discordo fortemente" para "concordo fortemente" entre pré e pós-teste e outra passou de "discordo fortemente" para "neutro".

Desta forma, a resposta para a Questão de Pesquisa 2 é que as práticas pedagógicas propostas têm, sim, impacto positivo sobre o interesse das crianças em leitura e aspectos correlatos, notadamente com respeito ao gosto de ler em casa e ao interesse na leitura em dispositivos digitais (computador, tablet e celular), bem como com respeito à compreensão de atitudes dos personagens de histórias lidas-vistas em desenho animado.

\section{Discussão}

Apesar da observação de indícios positivos apontados pelas médias pré e pós-testes com relação à compreensão textual, os resultados obtidos neste trabalho não apresentaram significância estatística, o que acontece com outros estudos que também não observam efeitos positivos sobre essa variável [Goux et al. 2017, Spinillo 2008]. Isso enfatiza como esta é uma questão problemática. Tais resultados também convergem com o trabalho empírico desenvolvido na proposta original do zReader [Guerra et al. 2018] onde, particularmente em crianças do Terceiro Ano, foi observada evolução melhor do grupo experimental nas medições de compreensão textual, mas sem significância estatística. Em comparação com o trabalho original [Guerra et al. 2018], este trabalho utilizou um número de sessões parecido (11 sessões com o aplicativo em relação a 10 sessões no original), distribuindo, entretanto, as sessões de forma mais esparsa ao longo do ano letivo, numa proporção de, no máximo, duas sessões por mês (o trabalho original reporta 1 sessão por semana). Cada sessão nossa durou, no entanto, 4 vezes mais que as sessões da proposta original, em função de todo o referencial pedagógico que embasou as interações com as crianças - a ideia foi a de dar mais tempo para elas evoluírem. No entanto, os resultados indicam a possibilidade de aumentar também o número de sessões como a 
Tabela 1. Estatística, atitudes e efeitos esperados para cada item avaliado

\begin{tabular}{|c|c|c|c|c|c|}
\hline Item & valor-p & $\begin{array}{l}\text { Delta } \\
\text { Cliff }\end{array}$ & $\begin{array}{l}\text { pré-pós } \\
(\%)\end{array}$ & $\begin{array}{l}\text { Atitude } \\
\text { prévia }\end{array}$ & Efeito \\
\hline 1. Eu gosto de ler & 0.24 & - & - & positiva & Sem significância estatística \\
\hline $\begin{array}{l}\text { 2.Eu queria ler historinhas toda se- } \\
\text { mana }\end{array}$ & 0.28 & - & - & positiva & Sem significância estatística \\
\hline 3.Eu gosto de ler historinhas em casa & 0.005 & 0.51 & $\begin{array}{l}\uparrow 63.46 \\
=25 \\
\downarrow 11.54\end{array}$ & positiva & $\begin{array}{l}\text { Significativo e positivo: } 63,46 \% \text { de } \\
\text { chance de atitude mais positiva após } \\
\text { as práticas, contra } 11,54 \% \text { de chance } \\
\text { de atitude mais negativa }\end{array}$ \\
\hline $\begin{array}{l}\text { 4.Eu gosto mais de ler historinhas no } \\
\text { celular do que no livrinho de papel }\end{array}$ & 0.00034 & 0.62 & $\begin{array}{l}\uparrow 71.15 \\
=20.51 \\
\downarrow 8.33\end{array}$ & neutra & $\begin{array}{l}\text { Significativo e positivo: } 71,15 \% \text { de } \\
\text { chance de atitude mais positiva após } \\
\text { as práticas, contra } 8,33 \% \text { de chance } \\
\text { de atitude mais negativa }\end{array}$ \\
\hline $\begin{array}{l}\text { 5.Eu gosto mais de ler historinhas no } \\
\text { tablet do que no livrinho de papel }\end{array}$ & 0.00056 & 0.65 & $\begin{array}{l}\uparrow 74.36 \\
=16.67 \\
\downarrow 8.97\end{array}$ & negativa & $\begin{array}{l}\text { Significativo e positivo: } 74,36 \% \text { de } \\
\text { chance de atitude mais positiva após } \\
\text { as práticas, contra } 8,97 \% \text { de chance } \\
\text { de atitude mais negativa }\end{array}$ \\
\hline $\begin{array}{l}\text { 6.Eu gosto mais de ler historinhas no } \\
\text { computador do que no livrinho de } \\
\text { papel }\end{array}$ & 0.00015 & 0.63 & $\begin{array}{l}\uparrow 73.08 \\
=17.31 \\
\downarrow 9.62\end{array}$ & negativa & $\begin{array}{l}\text { Significativo e positivo: } 73,08 \% \text { de } \\
\text { chance de atitude mais positiva após } \\
\text { as práticas, contra } 9,62 \% \text { de chance } \\
\text { de atitude mais negativa }\end{array}$ \\
\hline $\begin{array}{l}\text { 7.Eu converso em casa sobre as his- } \\
\text { torinhas que eu leio nos livrinhos }\end{array}$ & 0.47 & - & - & neutra & Sem significância estatística \\
\hline $\begin{array}{l}\text { 8. Quando eu vejo um desenho ani- } \\
\text { mado, eu consigo lembrar de al- } \\
\text { guma coisa parecida que aconteceu } \\
\text { comigo }\end{array}$ & 0.31 & - & - & neutra & Sem significância estatística \\
\hline $\begin{array}{l}\text { 9. Quando eu leio uma historinha eu } \\
\text { consigo lembrar de alguma coisa pa- } \\
\text { recida que aconteceu comigo }\end{array}$ & 0.058 & - & - & neutra & Sem significância estatística \\
\hline $\begin{array}{l}\text { 10.Quando eu vejo um desenho ani- } \\
\text { mado, eu sei quando os personagens } \\
\text { estão falando alguma coisa }\end{array}$ & 0.019 & 0.47 & $\begin{array}{l}\uparrow 64.74 \\
=17.95 \\
\downarrow 17.31\end{array}$ & neutra & $\begin{array}{l}\text { Significativo e positivo: } 64,74 \% \text { de } \\
\text { chance de atitude mais positiva após } \\
\text { as práticas, contra } 17,31 \% \text { de chance } \\
\text { de atitude mais negativa }\end{array}$ \\
\hline $\begin{array}{l}\text { 11. Quando eu leio uma historinha, } \\
\text { eu sei quando os personagens estão } \\
\text { falando alguma coisa }\end{array}$ & 0.0001 & 0.67 & $\begin{array}{l}\uparrow 74.36 \\
=19.23 \\
\downarrow 6.41\end{array}$ & negativa & $\begin{array}{l}\text { Significativo e positivo: } 74,36 \% \text { de } \\
\text { chance de atitude mais positiva após } \\
\text { as práticas, contra } 6,41 \% \text { de chance } \\
\text { de atitude mais negativa }\end{array}$ \\
\hline $\begin{array}{l}\text { 12. Quando eu vejo um desenho ani- } \\
\text { mado, eu sei quando os personagens } \\
\text { estão tristes ou alegres }\end{array}$ & 0.00004 & 0.66 & $\begin{array}{l}\uparrow 69.87 \\
=26.92 \\
\downarrow 3.21\end{array}$ & positiva & $\begin{array}{l}\text { Significativo e positivo: } 69,87 \% \text { de } \\
\text { chance de atitude mais positiva após } \\
\text { as práticas, contra } 3,21 \% \text { de chance } \\
\text { de atitude mais negativa }\end{array}$ \\
\hline $\begin{array}{l}\text { 13. Quando eu leio uma historinha, } \\
\text { eu sei quando os personagens estão } \\
\text { tristes ou alegres }\end{array}$ & 0.017 & 0.41 & $\begin{array}{l}\uparrow 51.28 \\
=38.46 \\
\downarrow 10.26\end{array}$ & positiva & $\begin{array}{l}\text { Significativo e positivo: } 51,28 \% \text { de } \\
\text { chance de atitude mais positiva após } \\
\text { as práticas, contra } 10,26 \% \text { de chance } \\
\text { de atitude mais negativa }\end{array}$ \\
\hline $\begin{array}{l}\text { 14. Quando eu leio uma historinha, } \\
\text { eu fico pensando no que eu faria se } \\
\text { eu fosse um dos personagens }\end{array}$ & 0.003 & 0.52 & $\begin{array}{l}\uparrow 64.1 \\
=24.36 \\
\downarrow 11.54\end{array}$ & neutra & $\begin{array}{l}\text { Significativo e positivo: } 64,1 \% \text { de } \\
\text { chance de atitude mais positiva após } \\
\text { as práticas, contra } 11,54 \% \text { de chance } \\
\text { de atitude mais negativa }\end{array}$ \\
\hline $\begin{array}{l}\text { 15. Quando eu leio uma historinha, } \\
\text { eu fico querendo ser algum dos per- } \\
\text { sonagens }\end{array}$ & 0.1 & - & - & positiva & Sem significância estatística \\
\hline
\end{tabular}


próxima possibilidade a ser testada empiricamente em busca de significância estatística sobre a evolução da compreensão textual em crianças do Terceiro Ano.

Já no que que diz respeito à avaliação do interesse pela leitura, as observações são bastante relevantes. Dos itens influenciados positivamente pela prática pedagógica com o aplicativo móvel, temos alguns relacionados ao reconhecimento e emoções e diálogos dos personagens, este último sendo uma habilidade explicitamente deficiente em mais da metade das crianças do país (bem mais que isso, em alumas regiões) que concluem o ciclo de alfabetização, conforme já discutimos na Seção 1.

O incentivo significativo à leitura em casa é outro ponto proeminente entre os resultados qualitativos, em especial quanto às perspectivas futuras das crianças, uma vez que já foi observado que jovens dos 11 aos 14 anos de idade que leem diariamente em seu tempo livre têm duas vezes mais chances de ter um nível de leitura acima da média de sua idade em relação aos jovens que não têm esse costume [Clark and Teravainen-Goff 2020]. Outrossim, o acesso a recursos educacionais pode ser observado como migrando do conteúdo impresso em papel para opções digitais [Bando et al. 2017], o que, nesse mesmo sentido, traz como outro resultado relevante quanto às perspectivas futuras das crianças a questão das práticas pedagógicas com o zReader estarem associadas a uma maior afetividade em relação à leitura em meios digitais como computadores, tablets e celulares.

Por fim, outro ponto digno de nota é a questão da leitura colaborativa, em grupos. Ato que, de certa forma, é incentivado pela própria dinâmica dos jogos do zReader (que culminam na gravação de um desenho animado com diferentes crianças podendo dar voz a diferentes personagens) e reforçado pela prática pedagógica proposta, fazendo com que as crianças interajam bastante já na fase de leitura das narrativas - dentro dos grupos e entre os grupos, mediante intervenção docente. A leitura colaborativa, ainda que executada através de um sistema de anotações compartilhadas, de forma bem diversa da proposta nesse trabalho, já pode ser associada a uma melhoria de desempenho em compreensão textual [Chen and Chen 2014], o que pode beneficiar as crianças também nesse sentido, a longo prazo, no caso de uma exposição por mais tempo às práticas com a ferramenta.

\section{Conclusão}

Este trabalho apresentou uma prática pedagógica aliada a um recurso tecnológico em uma turma de Terceiro Ano do Ensino Fundamental. A ideia central foi a de provocar no aluno a curiosidade e estimular sua participação nas atividades de leitura digital e analisar reflexos disso no que diz respeito a compreensão textual e interesse pela leitura.

Os resultados foram positivos e significativos com relação ao interesse das crianças pela leitura e aspectos correlatos. Com relação à compreensão textual, apesar de encontrarmos indícios amostrais de melhoria, pela evolução das médias realizadas nos pré e pós-testes, os resultados não apresentaram significância estatísticas. Há de ressaltarse a amostra pequena disponível e a natureza quase-experimental dos procedimentos metodológicos como fatores limitantes. Assim, outros estudos estão sendo planejados para aprofundar essa discussão, variando sensivelmente alguns fatores importantes como a quantidade de sessões didáticas com a ferramenta.

Mas, de uma forma geral, foi possível notar o desenvolvimento das crianças, assim como o interesse pela leitura, inclusive em diversos aspectos não observados formalmente, 
como o envolvimento pessoal com as histórias, o interesse em debater temas abordados nas narrativas, de viver seus personagens etc. Foram notórias também, as habilidades com relação à manipulação dos tablets e do zReader, pois os alunos, em poucas semanas, já conseguiam manusear corretamente a ferramenta, fazer as interações dos jogos e gravar os desenhos animados. Vemos, assim, a importância de uma prática pedagógica aliada a uma concepção clara de ensino e aprendizagem em que o professor tem noção do sujeito que quer formar e que objetivos quer atingir. A intervenção realizada durante todo esse processo de aplicação do zReader foi de grande relevância para o desenvolvimento das crianças e a prática utilizada apresentou efeitos positivos sobre a problemática.

\section{Referências}

Brasil 2016. Ministério da Educação. Avaliação nacional da alfabetização (ana): documento básico. Brasília-DF: MEC/INEP, 2016. https://www.gov.br/inep/pt-br/areas-deatuacao/avaliacao-e-exames- educacionais/saeb/resultados. Acessado em: 01 de jul de 2020.

Instituto Pró-Livro 2019. Relatos de leitura no Brasil. 5.ed. 2019. https://www.prolivro.org.br/pesquisas-retratos-da-leitura/as-pesquisas-2/. Acessado em: 16 de set de 2020 .

Bando, R., Gallego, F., Gertler, P., and Fonseca, D. R. (2017). Books or laptops? the effect of shifting from printed to digital delivery of educational content on learning. Economics of Education Review, 61:162-173.

Barra, A. S. B. (2014). Uma análise do conceito de zona de desenvolvimento proximal. Revista da Universidade Vale do Rio Verde, 12(1):765-774.

Chen, C.-M. and Chen, F.-Y. (2014). Enhancing digital reading performance with a collaborative reading annotation system. Computers \& Education, 77:67-81.

Clark, C. and Teravainen-Goff, A. (2020). Children and young people's reading in 2019: Findings from our annual literacy survey. national literacy trust research report. National Literacy Trust.

Cliff, N. (1993). Dominance statistics: Ordinal analyses to answer ordinal questions. Psychological Bulletin, 114(3):494-509.

Ferreiro, E. and Teberosky, A. (1985). Psicogênese da língua escrita. Porto Alegre: Artes Médicas.

Gil, A. C. (2010). Como elaborar projetos de pesquisa. São Paulo: Atlas, 5 edition.

Goux, D., Gurgand, M., and Maurin, E. (2017). Reading enjoyment and reading skills: Lessons from an experiment with first grade children. Labour Economics, 45:17-25. Field experiments in labor economics and social policies.

Guerra, F., , F. L. G., Serey, D., and de Figueiredo, J. C. A. (2019). Syllabic keyboard: A literacy game for motivating first grade children to read. In Proc. of XXX Simpósio Brasileiro de Informática na Educação, SBIE, Brasília.

Guerra, F., Santos, J. A., Serey, D., and de Figueiredo, J. C. A. (2018). z-reader: a mobile game suite for improving children's reading skills and behavior. In Proc. of XXIX Simpósio Brasileiro de Informática na Educação, SBIE, page 565, Fortaleza, Ceará. 
Johnston, L. W. (1970). Student's t-test. Journal of Quality Technology, 2(4):243-245.

Libâneo, J. C. (2013). Didática. São Paulo: Editora Cortez, 2 edition.

Prodanov, C. C. and de Freitas, E. C. (2013). Metodologia do trabalho científico: Métodos e técnicas da pesquisa e do trabalho acadênico. Novo Hamburgo: Feevale, 2 edition.

Sawilowsky, S. (2009). New effect size rules of thumb. Journal of Modern Applied Statistical Methods, 8(2):467-474.

Seabra, A. G. and Capovilla, F. C. (2010). Teste de Competência de Leitura de Palavras e Pseudopalavras (TCLPP). São Paulo, SP: Memnon, 1 edition.

Spinillo, A. G. (2008). O leitor e o texto: desenvolvendo a compreensão de textos na sala de aula. Interamerican Journal of Psychology, 42:29 - 40.

Takacs, Z. K., Swart, E. K., and Bus, A. G. (2015). Benefits and pitfalls of multimedia and interactive features in technology-enhanced storybooks: A meta-analysis. Review of Educational Research, 85(4):698-739.

Tatagiba, A. B. (2012). Creswell, john w. projeto de pesquisa: métodos qualitativo, quantitativo e misto; tradução magda lopes. 3 ed. porto alegre: Artmed, 296 páginas, 2010. Cadernos de Linguagem e Sociedade, 13(1):205-208.

Teberosky, A. and Colomer, T. (2003). Aprender a ler e a escrever: uma propsta construtivista. Porto Alegre: Artmed.

Tripp, D. (2005). Pesquisa-ação: uma introdução metodológica. Educação e Pesquisa, 31(3):443-466.

Wohlin, C., Runeson, P., Höst, M., Ohlsson, M., Regnell, B., and Wesslén, A. (2012). Experimentation in Software Engineering. Springer Berlin Heidelberg. 